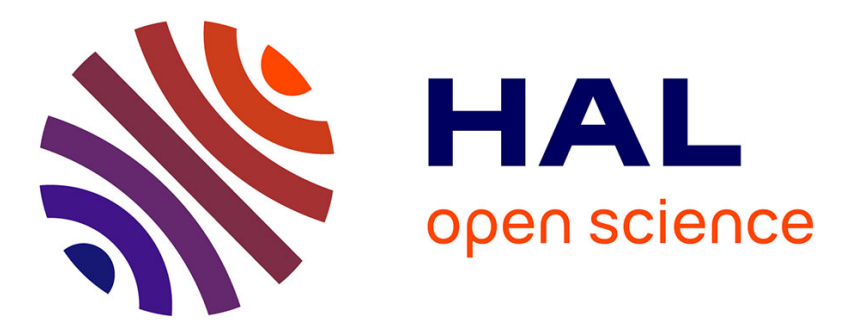

\title{
Stability study and dynamical analysis of the multicellular chopper
}

Philippe Djondiné, Jean-Pierre Barbot, Malek Ghanes

\section{To cite this version:}

Philippe Djondiné, Jean-Pierre Barbot, Malek Ghanes. Stability study and dynamical analysis of the multicellular chopper. International Journal of Simulation and Process Modelling, 2018, 13 (5), pp.486 - 495. hal-01896721

\section{HAL Id: hal-01896721 \\ https://hal.science/hal-01896721}

Submitted on 18 Oct 2018

HAL is a multi-disciplinary open access archive for the deposit and dissemination of scientific research documents, whether they are published or not. The documents may come from teaching and research institutions in France or abroad, or from public or private research centers.
L'archive ouverte pluridisciplinaire $\mathbf{H A L}$, est destinée au dépôt et à la diffusion de documents scientifiques de niveau recherche, publiés ou non, émanant des établissements d'enseignement et de recherche français ou étrangers, des laboratoires publics ou privés. 


\title{
Stability study and dynamical analysis of the multicellular chopper
}

\section{Philippe Djondiné*}

\author{
Department of Physics, \\ Faculty of Science, \\ The University of Ngaoundere, \\ Cameroon \\ and \\ QUARTZ EA 7393, ENSEA, \\ 6, avenue du Ponceau, CS20707 Cergy, \\ 95014 Cergy-Pontoise Cedex, France \\ Email: pdjondine@yahoo.fr \\ *Corresponding author
}

\section{Jean-Pierre Barbot and Malek Ghanes}

\author{
ECS-Lab, EA3649, ENSEA, \\ Cergy Cedex, Cergy-Pontoise 95014, France \\ and \\ QUARTZ EA 7393, ENSEA, \\ 6, avenue du Ponceau, CS20707 Cergy, \\ 95014 Cergy-Pontoise Cedex, France \\ Email: barbot@ensea.fr \\ Email: Malek.Ghanes@ensea.fr
}

\begin{abstract}
The dynamical properties of a two-cells chopper connected to a particular nonlinear load are described in this paper. Some interesting and complex attractors are obtained. We analyse the system by means of Lyapunov exponents, fractal dimension, Poincaré mapping, first return, bifurcation diagram and phase portraits, respectively. Our model is described by a continuous time three-dimensional non-autonomous system and displays two-scroll chaotic attractors for certain values of its parameters. The numerical simulation is used to figure out their chaotic attractors. The analysis results show clearly that this is a new chaotic system which deserves further detailed investigation. Finally, phase portraits are obtained by using MATLAB/Simulink, which validates the theoretical analysis results.
\end{abstract}

Keywords: chaotic behaviour; multicellular converter; nonlinear dynamics; dynamical properties; dissipative dynamics; equilibria and stability.

Reference to this paper should be made as follows: Djondiné, P., Barbot, J-P. and Ghanes, M. (2018) 'Stability study and dynamical analysis of the multicellular chopper', Int. J. Simulation and Process Modelling, Vol. 13, No. 5, pp.486-495.

Biographical notes: Philippe Djondiné received his $\mathrm{PhD}$ in Genie Electric and Electronic at the University of Cergy-Pontoise, France. He is a Lecturer at the Department of Physics, the University of Ngaoundere. His research interests are related to chaos and nonlinear phenomena in power converter.

Jean-Pierre Barbot is a Professor at ENSEA Cergy-Pontoise, France. He is currently the Director of the Quartz Laboratory EA 7393 and member of EPI Non-A at INRIA. After his graduation from the Ecole Normale Superieure of Cachan, he received his $\mathrm{PhD}$ degree in Automatic Control from the University of Paris XI (France) in 1989 and the HDR in 1997. His main research activities deal with sliding mode control and observation, system under sampling, hybrid system, delay system, synchronisation of chaotic system, normal form and recently compressive sensing. His main application domains are electrical machine, power converter.

Malek Ghanes received his MS degree and $\mathrm{PhD}$ in Applied Automatic and Informatics both from IRCCyN, Ecole Centrale Nantes, in 2002 and 2005, respectively. From September 2005 to September 2006, he was a Postdoctoral position at GReyC. Since September 2006 and November 2008, he is Associate Professor and Head of Automatic Department, respectively, at ENSEA, France. In November 2012, he obtained his Accreditation to Supervise Research (HDR) and qualified as a Full Professor. His research interests include observation and control of nonlinear system, with applications to electric and chaotic systems. 


\section{Introduction}

Multicells converters have grown from an attractive theoretical concept to industrial applications, especially for use in higher power applications (Erickson and Maksimovic, 2001; Dargahi et al., 2014; Meynard and Foch, 1992; Janghorbani et al., 2015; Lobsiger and Kolar, 2015; Hayashi et al., 2017) and they are well suited to packaging of renewable energy sources. Indeed, due to their modular structure, they can be combined easily (Meynard, 2014). In recent decades, it was discovered that most of static converters were the seat of unknown nonlinear phenomena in power electronics (Bernardo and Chi, 2002; Vazquez et al., 2016; Choupan et al., 2017; Hayashi et al., 2016; Hayashi and Ninomiya, 2016). It is for example the case of multicellular choppers that can exhibit unusual and sometimes chaotic behaviours. Obviously this may generate dramatic consequences. However, the usual averaged models do not allow to predicting nonlinear phenomena encountered. By nature, these models obscure the essential nonlinearities. To analyses these strange behaviours, it is necessary to use a nonlinear hybrid dynamical model (Barbot et al., 2007; Benmansour et al., 2010; La Rosa et al., 2000; Ahmad et al., 2015).

There have been many methods for detecting chaos from order. They include Poincaré sections, Lyapunov exponents (Skokos, 2017; Maffione et al., 2011), fast Lyapunov indicators (FLIs) (Lega et al., 2016; Barrio, 2016), smaller alignment index (SALI) and its generalised alignment index (Skokos and Manos, 2016), bifurcations, power spectra, frequency analysis, 0-1 test, geometrical criteria, and fractal basin boundaries, etc. Each of them has its advantages and drawbacks in classifying the attractors. For a system of any dimension, the Lyapunov exponents, as a method of the average exponential deviation of two nearby orbits in the phase space, are efficient to distinguish regular from chaotic orbits, but quite a long integration times are often needed before obtaining reliable limit values. In addition, a more sensitive indicator, the FLI of Froeschlé (Lega et al., 2016; Barrio, 2016) is an ideal method. Distinction methods between chaotic and ordered orbits such as the small alignment index and fast Lyapunov indicator firstly used to discuss dissipative system in (Huang and $\mathrm{Wu}, 2012$ ).

The main purpose of the present paper is to use numerical approaches to analyse the dynamical properties of a two-cells chopper connected to nonlinear load. The rest of this paper is organised as follows. Section 2, the two-cells chopper connected to a particular nonlinear load modelling and analysis of a switching cell are presented. Basic dynamical properties of the chaotic system are also investigated in Section 3. Finally, chaotic behaviour and simulation results are presented in Section 4.

\section{Multicell converter model}

The multicellular converters (Figure 1) are built starting from an association of a certain number of cells. At the output, one obtains $(p+1)$ levels $\left(0, \frac{E}{p}, \ldots, \frac{(p-1) E}{p}, E\right)$. This association in series allows to the output source $V_{s}$ to evolve on $(p+1)$ possible levels. As the orders of the switches of the cells of commutation are independent, one obtains $2^{p}$ possible combinations. Thus, it is necessary to ensure an equilibrated distribution of the voltage of the floating condensers. Under these conditions, one obtains the following property: The converter has $p-1$ floating voltages sources and the voltage of the capacity of index $k$ is $k \frac{E}{p}$. The control signal associated with each commutation cell is noted as $u_{i}$ where $i$ represents the number of cells of the topology. This signal will be equal to 1 when the upper switch of the cell is conducting and 0 when the lower switch of the cell is conducting.

To simplify the study and the notations, we will study the overlapping operation of a converter with two cells (Figure 2). Its function is to supply a passive load (RL) in series with another nonlinear load (Fortuna et al., 2001) connected in parallel with a capacitor. Four operating modes are then possible as shown in Figure 3. Note that the floating source takes part in the evolution of the dynamics of the system only to the third and fourth mode. In the third mode, the capacity discharges and charge during the fourth mode. Thus, if these two modes last same time with a constant charging current, then the average power transmitted by this floating source over one period of commutation is null. We also notice that these two modes make it possible to obtain by commutation the additional level $\frac{E}{2}$ on the output voltage $V_{s}$.

As the switches of each cell are regarded as ideals, their behaviour can be to model by a discrete state taking of the values 0 (on) or 1 (off). In practice, some of these states never will be visited for reasons of safety measures or following the strategy of order adopted or because of the structure of the converter him finally to even or comply with the rule of adjacency. The transitions are not necessarily controlled.

The system model can be represented by three differential equations giving its state space.

$$
\left\{\begin{array}{l}
L \frac{d i_{L}}{d t}=\left(u_{1}-u_{2}\right) v_{C}-v_{C_{l}}-R i_{L}+u_{2} D \\
C \frac{d v_{C}}{d t}=\left(u_{2}-u_{1}\right) i_{L} \\
C_{l} \frac{d v_{C_{l}}}{d t}=i_{L}-g\left(v_{C_{l}}\right)
\end{array}\right.
$$


Figure 1 p-cells chopper connected to RL load

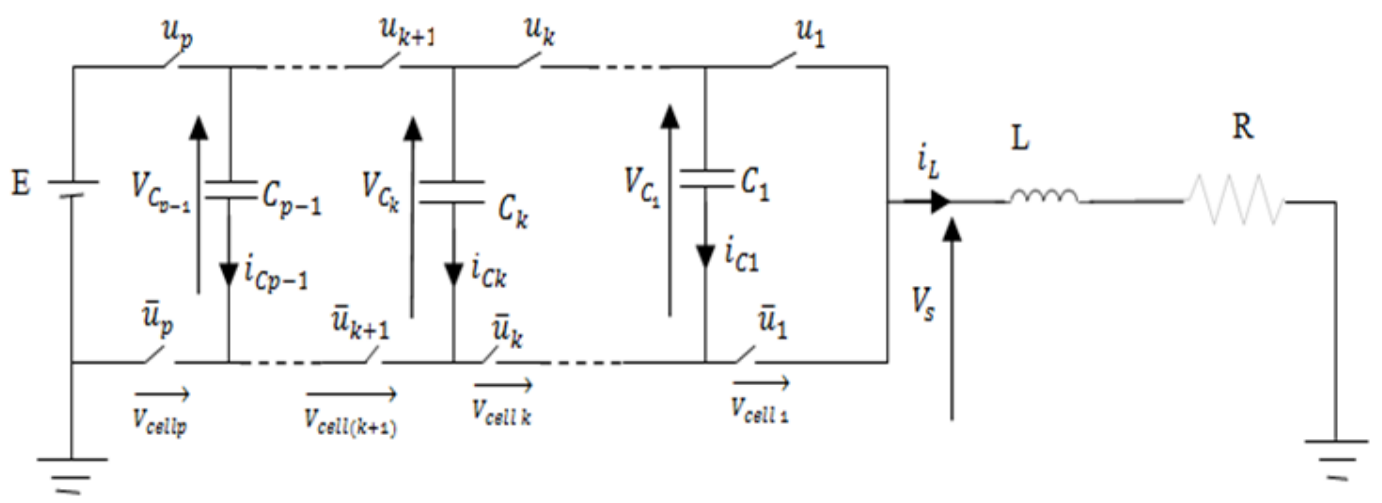

Figure 2 Two-cell chopper connected to a nonlinear load

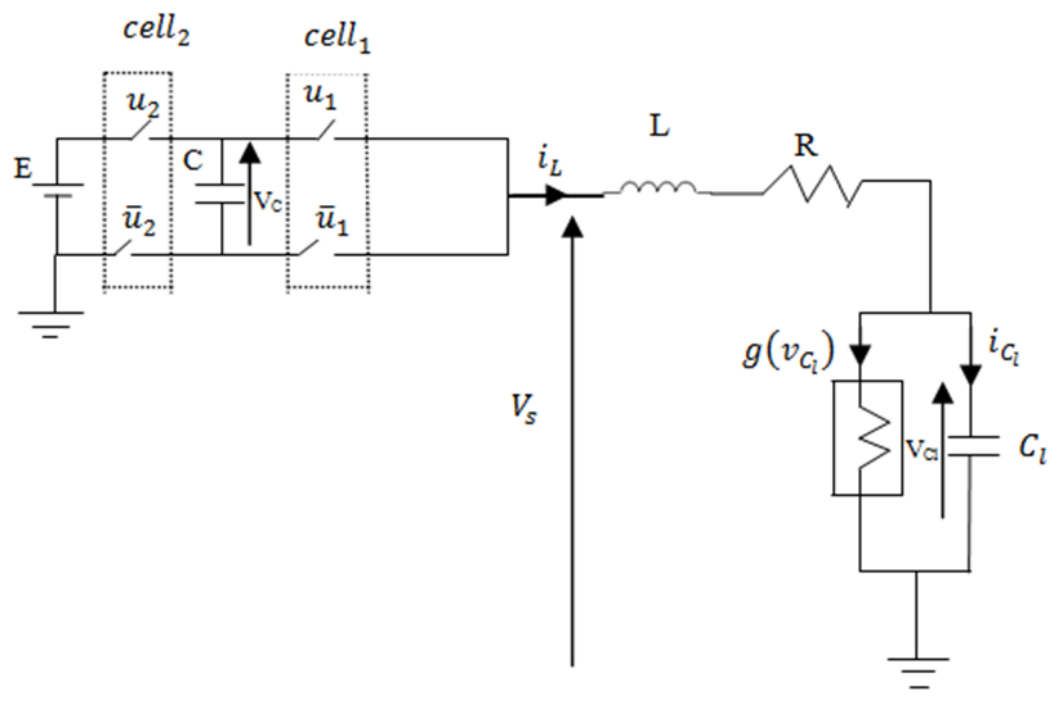

Figure 3 Switching cell and its configurations
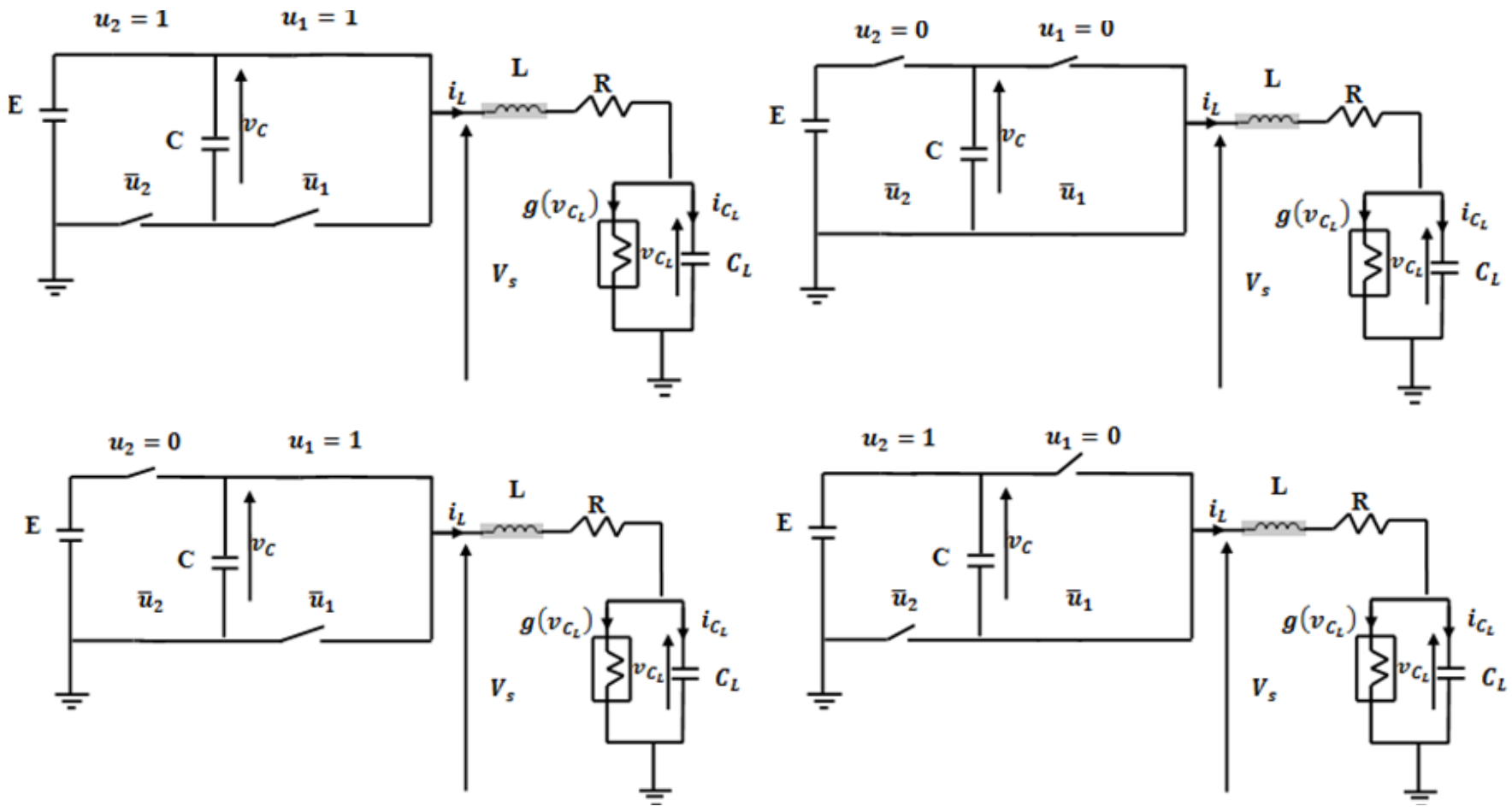
where $g(\cdot)$ is a piecewise-linear function

$$
g\left(v_{C_{l}}\right)=G_{b} v_{C_{l}}+\frac{1}{2}\left(G_{a}-G_{b}\right)\left(\left|v_{C_{l}}+1\right|-\left|v_{C_{l}}-1\right|\right)
$$

which is the mathematical representation of the characteristic curve of nonlinear load. The slopes of the inner and outer regions are $G_{a}$ and $G_{b}$, while $B_{p}$ indicates break points. The parameters of the circuit elements are fixed as $C=0.1 \mu \mathrm{F}, C_{l}=40 \mu \mathrm{F}, L=50 \mathrm{mH}, R=10 \Omega$, $E=100 \mathrm{~V}$

\section{Dynamical properties of system (1)}

\subsection{Equilibria and stability}

The equilibria of (1) can be calculated by solving the following algebraic equations simultaneously

$$
\left\{\begin{array}{l}
L \frac{d i_{L}}{d t}=\left(u_{1}-u_{2}\right) v_{C}-v_{C_{l}}-R i_{L}+u_{2} E=0 \\
C \frac{d v_{C}}{d t}=\left(u_{2}-u_{1}\right) i_{L}=0 \\
C_{l} \frac{d v_{C_{l}}}{d t}=i_{L}-g\left(v_{C_{l}}\right)=0
\end{array}\right.
$$

Rescaling equation (1) as $v_{C}=x_{2} B_{p}, v_{C_{l}}=x_{3} B_{p}, i_{L}=x_{1} G B_{p}$, $G=\frac{1}{R}, t=\frac{C}{G} \tau$ and then redefining $\tau$ as $\mathrm{t}$ the following set of normalised equations are obtained:

$$
\left\{\begin{array}{l}
\dot{x}_{1}=\beta\left(-\gamma x_{1}+\varepsilon x_{2}-x_{3}\right)+\alpha E \\
\dot{x}_{2}=\varepsilon x_{1} \\
\dot{x}_{3}=p\left(x_{1}-g\left(x_{3}\right)\right)
\end{array}\right.
$$

where $\varepsilon=u_{2}-u_{1}, p=\frac{C}{C_{l}}, \beta=\frac{C}{L G^{2}}, \gamma=R G, \alpha=\frac{\beta E}{B_{p}}$. or

Obviously $g\left(x_{3}\right)=b x_{3}+0.5(a-b)\left[\left|x_{3}+1\right|-\left|x_{3}-1\right|\right]$,

$$
g\left(x_{3}\right)= \begin{cases}b x_{3}+a-b & x_{3}>1 \\ a x_{3} & \left|x_{3}\right| \leq 1 \\ b x_{3}-a+b & x_{3}<-1\end{cases}
$$

Here $a=\frac{G_{a}}{G}, b=\frac{G_{b}}{G}$.

Now the dynamics of equation (3) depends on the parameters $\varepsilon, p, \beta, \gamma, a, b$ and $\alpha$. The circuit parameters used are then rescaled as: $p=25.10^{-4}, \alpha=2.10^{-2}, \beta=2.10^{-4}$, $a=-15, b=5, \gamma=1$. We thus find the equilibria:
Case 1: $\varepsilon=1$, i.e., $u_{1}=0 ; u_{2}=1$

- $x_{3}>1, \quad E_{1}=\left(\begin{array}{c}0 \\ \frac{b-a}{b}-\frac{\alpha}{\beta} \\ \frac{b-a}{b}\end{array}\right)=\left(\begin{array}{c}0 \\ -96 \\ 4\end{array}\right)$

- $\left|x_{3}\right| \leq 1, \quad E_{2}=\left(\begin{array}{c}0 \\ -\frac{\alpha}{\beta} \\ 0\end{array}\right)=\left(\begin{array}{c}0 \\ -100 \\ 0\end{array}\right)$

- $x_{3}<-1, \quad E_{3}=\left(\begin{array}{c}0 \\ \frac{a-b}{b}-\frac{\alpha}{\beta} \\ \frac{a-b}{b}\end{array}\right)=\left(\begin{array}{c}0 \\ -104 \\ -4\end{array}\right)$

Case 2: $\varepsilon=-1$, i.e., $u_{1}=1, u_{2}=0$

- $x_{3}>1, \quad E_{11}=\left(\begin{array}{c}0 \\ \frac{a-b}{b} \\ \frac{b-a}{b}\end{array}\right)=\left(\begin{array}{c}0 \\ -4 \\ 4\end{array}\right)$

- $\left|x_{3}\right| \leq 1, \quad E_{21}=\left(\begin{array}{l}0 \\ 0 \\ 0\end{array}\right)$

- $x_{3}<-1, \quad E_{31}=\left(\begin{array}{c}0 \\ \frac{b-a}{b} \\ \frac{a-b}{b}\end{array}\right)=\left(\begin{array}{c}0 \\ 4 \\ -4\end{array}\right)$

Case 3: $\varepsilon=0$

- $u_{1}=1, u_{2}=1$

a $\quad x_{3}>1, \quad E_{12}=\left(\begin{array}{c}\frac{\alpha+\left(\frac{\alpha}{\beta}-1\right) b}{1+b \gamma} \\ x_{2} \\ \frac{\gamma(-a+b)+\frac{\alpha}{\beta}}{1+b \gamma}\end{array}\right)=\left(\begin{array}{c}80 \\ x_{2} \\ 20\end{array}\right)$ 
$\mathrm{b} \quad\left|x_{3}\right| \leq 1, \quad E_{22}=\left(\begin{array}{c}\frac{a}{\beta} \\ \frac{\alpha}{1+a \gamma} \\ x_{2} \\ \frac{\alpha}{\beta} \\ 1+a \gamma\end{array}\right)=\left(\begin{array}{c}\frac{750}{7} \\ x_{2} \\ -\frac{50}{7}\end{array}\right)$

that does not belong to the interval, so there is not an equilibrium point.

$\mathrm{c} \quad x_{3}<-1, \quad E_{32}=\left(\begin{array}{c}\frac{-a+\left(1+\frac{\alpha}{\beta}\right) b}{1+b \gamma} \\ x_{2} \\ \frac{\gamma(a-b)+\frac{\alpha}{\beta}}{1+b \gamma}\end{array}\right)=\left(\begin{array}{c}\frac{260}{7} \\ x_{2} \\ \frac{40}{3}\end{array}\right)$

that does not belong to the interval, so there is not an equilibrium point.

- $u_{1}=0, u_{2}=0$

$$
\begin{aligned}
& \text { a } \quad x_{3}>1, \quad E_{13}=\left(\begin{array}{c}
\frac{a-b}{1+b \gamma} \\
x_{2} \\
\frac{-\gamma(a-b)}{1+b \gamma}
\end{array}\right)=\left(\begin{array}{c}
-\frac{10}{3} \\
x_{2} \\
\frac{10}{3}
\end{array}\right) \\
& \mathrm{b} \quad\left|x_{3}\right| \leq 1, \quad E_{23}=\left(\begin{array}{c}
0 \\
x_{2} \\
0
\end{array}\right) \\
& \mathrm{c} \quad x_{3}<-1, \quad E_{23}=\left(\begin{array}{c}
\frac{-a+b}{1+b \gamma} \\
x_{2} \\
\frac{-\gamma(-a+b)}{1+b \gamma}
\end{array}\right)=\left(\begin{array}{c}
\frac{10}{3} \\
x_{2} \\
-\frac{10}{3}
\end{array}\right)
\end{aligned}
$$

Let us study the stability of different equilibrium points.

1 For $x_{3}>1$, the Jacobian matrix is defined as

$$
\left[\begin{array}{ccc}
-\beta \gamma & \beta \varepsilon & -\beta \\
\varepsilon & 0 & 0 \\
p & 0 & -b p
\end{array}\right]=\left[\begin{array}{ccc}
-2.10^{-4} & -2.10^{-4} \varepsilon & -2.10^{-4} \\
\varepsilon & 0 & 0 \\
25.10^{-4} & 0 & -125.10^{-4}
\end{array}\right]
$$

The eigenvalues are:

a If $\varepsilon= \pm 1, \lambda_{1}=0.0140, \lambda_{2}=-0.0141 ; \lambda_{3}=-0.0126$

Here $\lambda_{1}$ is a positive real number, $\lambda_{2}$ and $\lambda_{3}$ are two negatives real numbers.
Therefore, the equilibrium $E_{1}=\left(\begin{array}{c}0 \\ -96 \\ 4\end{array}\right)$ and $E_{11}=\left(\begin{array}{c}0 \\ -4 \\ 4\end{array}\right)$ are a saddle point in the plane $\left(x_{1}, x_{2}\right)$ and $\left(x_{1}, x_{3}\right)$; these equilibrium are unstable.

$\mathrm{b} \quad$ If $\varepsilon=0, \lambda_{1}=-0.0002 ; \lambda_{2}=-0.0125, \lambda_{3}=0$

Then, $E_{12}=\left(\begin{array}{c}80 \\ x_{2} \\ 20\end{array}\right)$ and $E_{13}=\left(\begin{array}{c}-\frac{10}{3} \\ x_{2} \\ \frac{10}{3}\end{array}\right)$ are stable

equilibrium points within the meaning of Lyapunov for all $x_{2}$.

2 For $\left|x_{3}\right| \leq 1$, the Jacobian matrix is defined as

$$
\left[\begin{array}{ccc}
-\beta \gamma & \beta \varepsilon & -\beta \\
\varepsilon & 0 & 0 \\
p & 0 & -a p
\end{array}\right]=\left[\begin{array}{ccc}
-2.10^{-4} & -2.10^{-4} \varepsilon & -2.10^{-4} \\
\varepsilon & 0 & 0 \\
25.10^{-4} & 0 & -375.10^{-4}
\end{array}\right]
$$

Three characteristic values of the Jacobian matrix $\mathrm{J}$ can be obtained from $|\lambda I-J|=0$ as follows:

a If $\varepsilon= \pm 1 ; \lambda_{1}=0.0140 ; \lambda_{2}=-0.0143 ; \lambda_{3}=-0.0375$

Here $\lambda_{1}$ is a positive real number, $\lambda_{2}$ and $\lambda_{3}$ are two negatives real numbers.

Therefore, the equilibrium $E_{2}=\left(\begin{array}{c}0 \\ -100 \\ 0\end{array}\right)$ and $E_{21}=\left(\begin{array}{l}0 \\ 0 \\ 0\end{array}\right)$ are a saddle point in the plane $\left(x_{1}, x_{2}\right)$ and $\left(x_{1}, x_{3}\right)$; these equilibrium are unstable.

b If $\varepsilon=0 ; \lambda_{1}=-0.0002 ; \lambda_{2}=-0.0375 ; \lambda_{3}=0$

Then, $E_{23}=\left(\begin{array}{c}0 \\ x_{2} \\ 0\end{array}\right)$ is stable equilibrium point

within the meaning of Lyapunov for all $x_{2}$.

3 For $x_{3}<-1$, the Jacobian matrix is defined as

$$
\left[\begin{array}{ccc}
-\beta \gamma & \beta \varepsilon & -\beta \\
\varepsilon & 0 & 0 \\
p & 0 & -b p
\end{array}\right]=\left[\begin{array}{ccc}
-2.10^{-4} & -2.10^{-4} \varepsilon & -2.10^{-4} \\
\varepsilon & 0 & 0 \\
25.10^{-4} & 0 & -125 \cdot 10^{-4}
\end{array}\right]
$$


The eigenvalues are:

a If $\varepsilon= \pm 1 ; \lambda_{1}=0.0140 ; \lambda_{2}=-0.0141 ; \lambda_{3}=-0.0126$

Here $\lambda_{1}$ is a positive real number, $\lambda_{2}$ and $\lambda_{3}$ are two negatives real numbers.

Therefore, the equilibrium $E_{3}=\left(\begin{array}{c}0 \\ -104 \\ 4\end{array}\right)$ and $E_{31}=\left(\begin{array}{c}0 \\ 4 \\ -4\end{array}\right)$ are a saddle point in the plane $\left(x_{1}, x_{2}\right)$ and $\left(x_{1}, x_{3}\right)$; these equilibrium are unstable.

b If $\varepsilon=0 ; \lambda_{1}=-0.0002 ; \lambda_{2}=-0.0125 ; \lambda_{3}=0$

Then, $E_{12}=\left(\begin{array}{c}80 \\ x_{2} \\ 20\end{array}\right)$ and $E_{13}=\left(\begin{array}{c}-\frac{10}{3} \\ x_{2} \\ \frac{10}{3}\end{array}\right)$ are stable

equilibrium points within the meaning of

Lyapunov for all $x_{2}$.

\subsection{Symmetry and invariance}

Symmetry on the $x_{2}$-axis is due to invariance of the equations under the transformation $\left(x_{1}, x_{2}, x_{3}\right) \rightarrow\left(x_{1},-x_{2}\right.$, $\left.x_{3}\right)$. The system has rotational symmetry in the plane $\left(x_{1}, x_{3}\right)$ (Wei and Yang, 2011; Dadras and Momeni, 2009).

\subsection{Dissipativity}

For system (3), we can obtain

$$
\nabla V=\frac{\partial \dot{x}_{1}}{\partial x_{1}}+\frac{\partial \dot{x}_{2}}{\partial x_{2}}+\frac{\partial \dot{x}_{3}}{\partial x_{3}}= \begin{cases}-\beta \gamma-p b & \text { if }\left|x_{3}\right|>0 \\ -\beta \gamma-p a & \text { if }\left|x_{3}\right| \leq 0\end{cases}
$$

As long as $(-\beta \gamma-p b)<0$ our system (3) is dissipative. Thus the volume elements are contracting. After a time unit this contraction reduces a volume $V_{0}$ by a factor $e^{-(\beta \gamma+p b) t}$. Which means that each volume containing the trajectory of this dynamical system converges to zero as $t \rightarrow \infty$ at exponential rate $(\beta \gamma+p b)$. Therefore, all system orbits are ultimately confined to a specific subset having zero volume and the asymptotic motion settles onto an attractor (Wei and Yang, 2011; Dadras and Momeni, 2009; Zhou et al., 2008; Li et al., 2009; Djondiné et al., 2014).

\subsection{Lyapunov exponent and fractional dimension}

The Lyapunov exponents generally refer to the average exponential rates of divergence or convergence of nearby trajectories in the phase space. If there is at least one positive Lyapunov exponent, the system can be defined to be chaotic. Thus,
- for the case $\varepsilon= \pm 1$, we find that the Lyapunov exponents have the values: $l_{1}=0.0318, l_{2}=-0.0319$, $l_{3}=-0.0128$. Therefore, the Lyapunov dimension of this system is:

$$
D_{L}=j+\frac{\sum_{i=1}^{j} l_{i}}{\left|l_{j+1}\right|}=2+\frac{0.0318-0.0319}{-0.0128}=2.0078125
$$

- for the case $\varepsilon=0$, we find that the Lyapunov exponents have the values: $l_{1}=-1.4029^{-4} ; l_{2}=0 ; l_{3}=-0.0126$. The Lyapunov dimension of this system is:

$$
D_{L}=j+\frac{\sum_{i=1}^{j} l_{i}}{\left|l_{j+1}\right|}=2+\frac{1.4029^{-4}}{|-0.0126|}=1.98886587
$$

This means that our system is chaotic since one of the Lyapunov exponents is positive and the Lyapunov dimensions of the system are fractional. The null Lyapunov exponent is obviously related to the critical nature between expansion and contracting nature of different directions in phase space. The chaotic behaviour for this system can also be shown by plotting the separation of two nearby trajectories.

\subsection{Poincaré section, first return and bifurcation diagram}

The Poincare section is computed for $x_{1}=0$ when the frequency is $20 \mathrm{~Hz}$. From Figure 4, it can be seen that the symmetry (Djondiné et al., 2013) is around the nominal voltage capacitor $V_{C n}$ that is $50 \mathrm{~V}$.

The first return map is computed by the voltage of nonlinear load $\left(x_{3}\right)$ for each minimum of $x_{3}$ which is detected with $\dot{x}_{1}=0=0$ and $\left|x_{1}\right|<0.01$. From Figure 5(a), it can be seen that there is a folding point at each end of the cross and obviously symmetry occurs (Dang-Vu and Delcarte, 2000).

Figure 4 The Poincaré section of $x_{1}-x_{2}$ plane

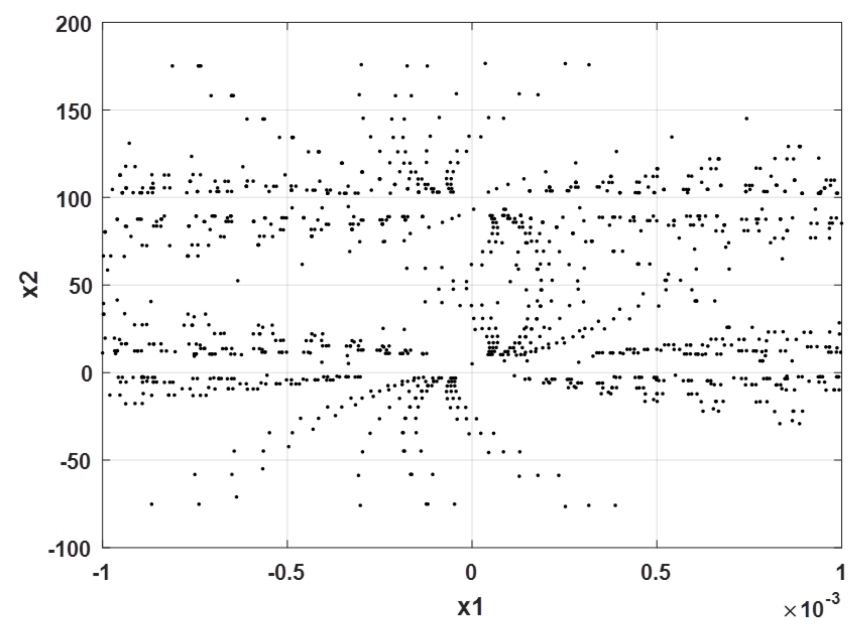


Figure 5 (a) First return map (b) Bifurcation diagram (see online version for colours)

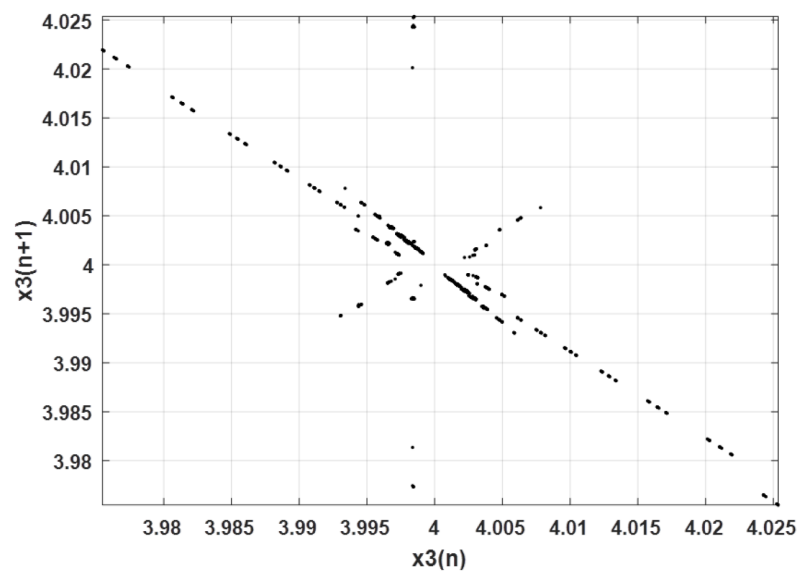

(a)

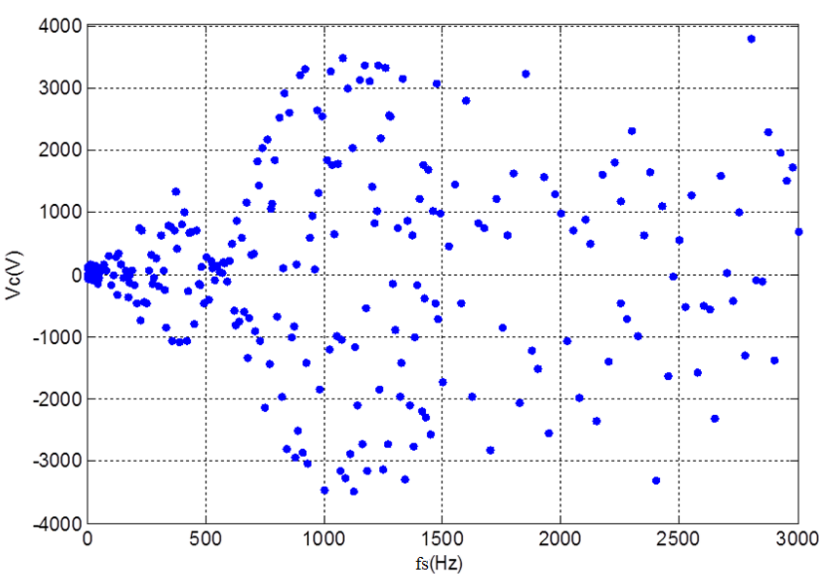

(b)

Figure 6 Phase portraits of the system, (a) $C=0.01 \mu \mathrm{F}$ (b) $C=0.1 \mu \mathrm{F}$ (c) $C=0.5 \mu \mathrm{F}$ (d) $C=1 \mu \mathrm{F}$ (e) $C=10 \mu \mathrm{F}$ (f) $C=100 \mu \mathrm{F}$

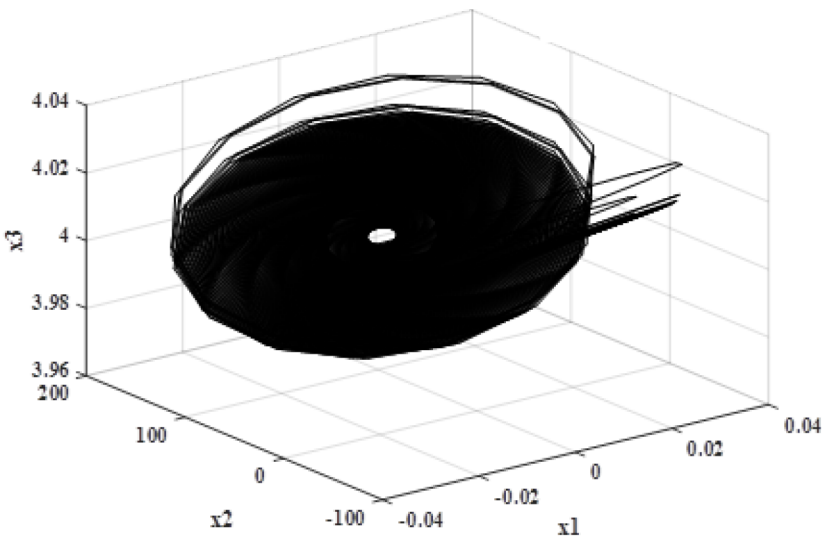

(a)

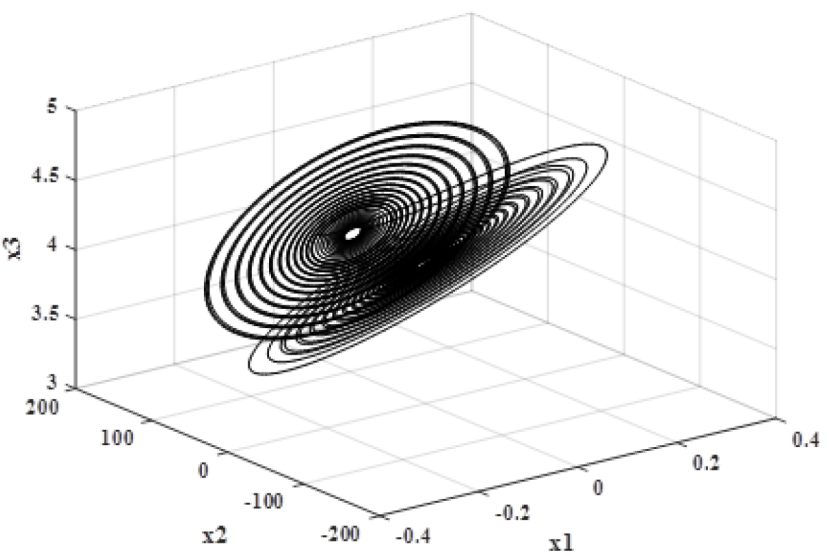

(c)

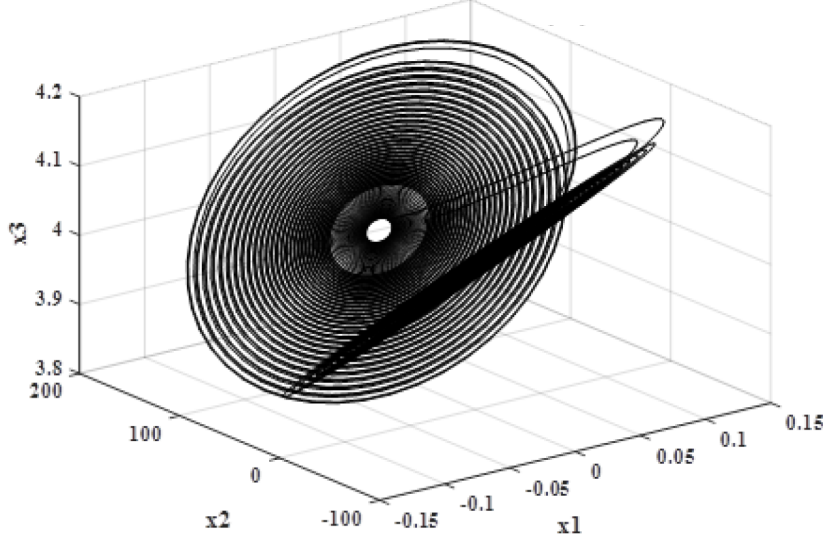

(b)

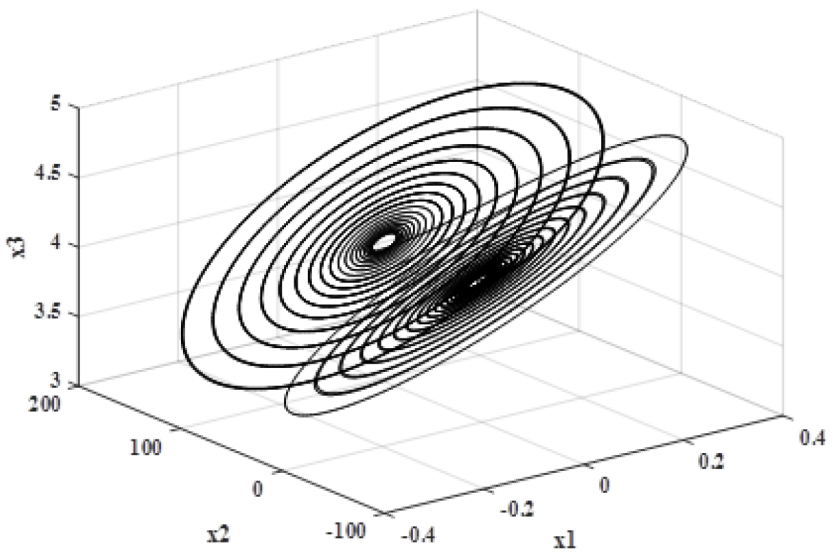

(d) 
Figure 6 Phase portraits of the system, (a) $C=0.01 \mu \mathrm{F}$ (b) $C=0.1 \mu \mathrm{F}$ (c) $C=0.5 \mu \mathrm{F}$ (d) $C=1 \mu \mathrm{F}$ (e) $C=10 \mu \mathrm{F}$ (f) $C=100 \mu \mathrm{F}$ (continued)

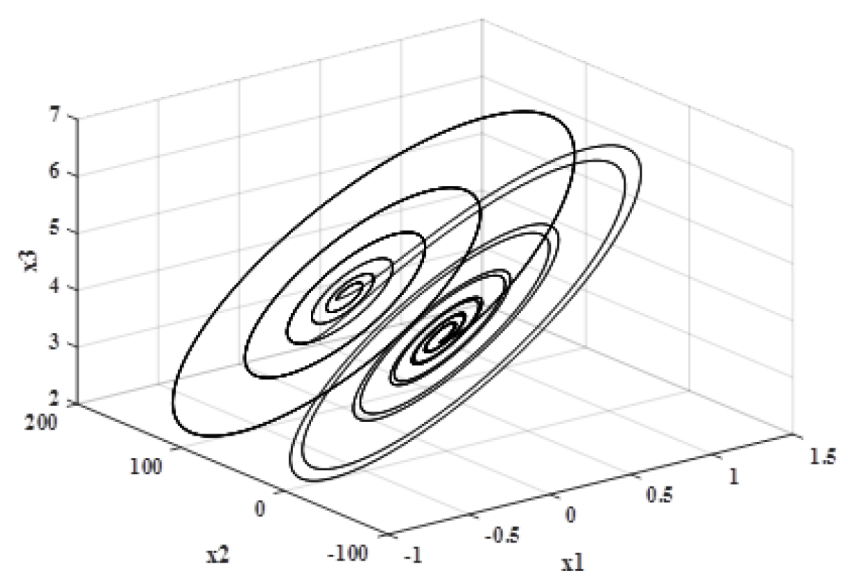

(e)

From bifurcation diagram [Figure 5(b)] it can be seen that the system is in the chaos between $1 \mathrm{~Hz}$ and $30 \mathrm{~Hz}$. As the frequency increases, the system behaviour stays chaotic and as maximum amplitude at the resonance frequency $f_{s}=\frac{\sqrt{C+C_{l}}}{2 \pi \sqrt{L C C_{l}}}=2,253.6 \mathrm{~Hz}$, the load current $x_{1}$ gets the maximum value of $5 \mathrm{~A}$. When the switching frequency is higher than the resonance frequency, the amplitude decreases and finally the behaviour passes from strange attractor to an equilibrium point.

\subsection{Observation of chaotic dynamics}

This nonlinear system exhibits the double-scroll chaotic attractor. It should be pointed out that, with different parameters, system (3) can evolve to other complex dynamics such as single-scroll chaotic attractor and periodic orbit (Huang and Zhao, 2016). In this system, the capacitor $C$ is a parameter of control and the value of $C$ can be changed within a certain range. When the parameter $C$ is changed, the chaos behaviour of this system can effectively be controlled. In the numerical simulation, the initial values of the system (3) are $(0,5,4)$. Using MATLAB program, the numerical simulation have been completed. This nonlinear system exhibits the complex and abundant of the chaotic dynamics behaviours, the strange attractors (Tremori et al., 2016) are shown in Figure 6. These phase portrait are obtained by solving equations (3) by means of Runge-Kutta method for step size of 0.000001 . At the beginning of simulation $u_{1}=u_{2}=0$. Now is clear that the double scroll attractor has a structure quite different from well-known Lorenz, Rössler and Chua attractors (Buscarino et al., 2011) since the double scroll (Koubaa, 2016) structure has not observed with the latter attractors.

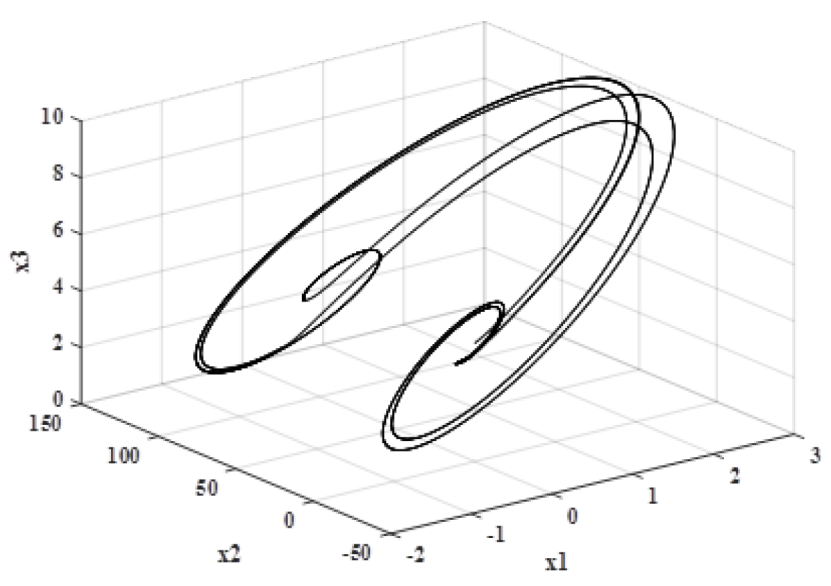

(f)

- for $C=0.01$ to $0.1 \mu \mathrm{F}$, system (3) is chaotic, and there are several periodic windows in the chaotic band, as shown in Figures 6(a)-6(b)

- $\quad$ for $C=0.5$ to $1 \mu \mathrm{F}$, systems (3) are some quasi-periodic loops and also call a reverse period-doubling bifurcation window, as shown in Figures 6(c)-6(d).

- for $C=10$ to $100 \mu \mathrm{F}$, there is a reverse period-doubling bifurcation window too, as shown in Figures 6(e)-6(f).

\section{Conclusions}

In this paper, the dynamics of a two-cells chopper associated to a particular nonlinear load has been reported and confirmed analytically and numerically. Some basic properties of the system including invariance, dissipativity, equilibria and their stability and Lyapunov exponents have been investigated. The particular interest is that our system can generate different scroll chaotic attractors with variation of a parameter of the circuit. The topological structure of the new system should be completely and thoroughly investigated. According to the analysis above, the two-cells converter with nonlinear load structure belongs to strongly nonlinear system, and its performance can be easily affected when the circuit parameters are varied. Therefore, the parameters should be chosen appropriately according to the research results. The analysis methods and research findings will possess an important reference value to engineering design and performance analysis. It is expected that more detailed theory analyses and simulation investigations will be provided in a forthcoming paper. 


\section{References}

Ahmad, N., Abdul Ghani, N., Kamil, A.A. and Tahar, R.B.M. (2015) 'Modelling the complexity of emergency department operations using hybrid simulation', International Journal of Simulation and Process Modelling, Vol. 10, No. 4, pp.360-371.

Barbot, J-P., Saadaoui, H., Djemai, M. and Manamanni, N. (2007) 'Nonlinear observer for autonomous switching systems with jumps', Nonlinear Analysis: Hybrid Systems, Vol. 1, No. 4, pp.537-547.

Barrio, R. (2016) 'Theory and applications of the orthogonal fast lyapunov indicator (OFLI and OFLI2) methods', in Skokos, C. et al. (Eds.): Chaos Detection and Predictability, Lecture Notes, pp.55-92.

Benmansour, K., Tlemani, A., Djemai, M. and de Leon, J. (2010) 'A new interconnected observer design in power converter: theory and experimentation', Nonlinear Dynamics and Systems Theory, Vol. 10, No. 3, pp.211-224.

Bernardo, M.D. and Chi, K.T. (2002) Bifurcation and Chaos in Power Electronics: An Overview in Nonlinear Dynamics in Engineering, edited by G. Chen, World Scientific, New York.

Buscarino, A., Fortuna, L., Frasca, M. and Sciuto, G. (2011) 'Design of time-delay chaotic electronic circuits', IEEE Transactions on Circuits and Systems I: Regular Papers, Vol. 58, No. 8, pp.1888-1896.

Choupan, R., Nazarpour, D. and Golshannavaz, S. (2017) 'A simple unit cell structure for an efficient sketch of series-connected multilevel inverters', International Journal of Circuit Theory and Applications, Vol. 45, No. 10, pp.1397-1417.

Dadras, S. and Momeni, H.R. (2009) 'A novel three-dimensional autonomous chaotic system generating two, three and four-scroll attractors', Physics Letters A, Vol. 373, No. 40, pp.3637-3642.

Dang-Vu, H. and Delcarte, C. (2000) Bifurcation et chaos : Une introduction a la dynamique contemporaine avec des programmes en Pascal, Fortran et Mathématica, Ellipses, Paris.

Dargahi, V., Abarzadeh, M., Khoshbar Sadigh, A. and Dargahi, S. (2014) 'Elimination DC voltage sources and reduction of power switches voltage stress in stacked multicell converters: analysis, modeling, and implementation', International Transactions on Electrical Energy Systems, Vol. 24, No. 5, pp.653-674.

Djondiné, P., Ghanes, M., Barbot, J-P. and Essimbi, B. (2014) 'Dynamical behaviors of multicellular chopper', Journal of Control Science and Engineering, Vol. 2, No. 1, pp.35-42.

Djondiné, P., He, R., Ghanes, M. and Barbot, J-P. (2013) 'Chaotic behavior study for serial multicellular chopper connected to nonlinear load', Proceedings of the 3rd International Conference on Systems and Control, 29-31 October, Algiers, Algeria.

Erickson, R. and Maksimovic, D. (2001) Fundamentals of Power Electronics, 2nd ed., Dordrecht, The Netherlands, 576pp, ISBN 0-7923-7270-0.

Fortuna, L., Arena, P., Balya, D. and Zarandy, A. (2001) 'A cellular neural networks: paradigm for nonlinear spatio-temporal processing', IEEE Circuits and Systems Magazine, Vol. 1, No. 4, pp.6-21.

Hayashi, Y. and Ninomiya, T. (2016) 'Analysis and prototyping of multicellular DC-DC transformer for environmentally friendly data centers', Journal of Energy and Power Engineering, Vol. 10, No. 5, pp.313-323.
Hayashi, Y., Matsugaki, Y. and Ninomiya, T. (2016) 'Fault tolerant operation of ISOP multicell DC-DC converter using active gate controlled $\mathrm{SiC}$ protection switch', Journal of Engineering, Vol. 2016, Article ID 7345232, 8pp.

Hayashi, Y., Matsugaki, Y. and Ninomiya, T. (2017) 'Capacitively isolated multicell DC-DC transformer for future DC distribution system', IEEJ Journal of Industry Applications, Vol. 6, No. 4, pp.268-277.

Huang, G-Q. and Wu, X. (2012) 'Analysis of new four-dimensional chaotic circuits with experimental and numerical methods', International Journal of Bifurcation and Chaos, Vol. 22, No. 2, 1250042, 13pp.

Huang, Z. and Zhao, H. (2016) 'Construction ressource scheduling with chaotic particule swarm optimisation', International Journal of Simulation and Process Modelling, Vol. 11, No. 1, pp.1-8.

Janghorbani, M., Javadi, S. and Khosravi, M. (2015) 'Nonlinear phenomena in power electronic: chaotic behavior of Buck converters', Indian Journal of Fundamental and Applied Life Sciences, Vol. 5, No. 1, pp.4122-4128.

Koubaa, K. (2016) 'Routes to chaos and bifurcation analysis in a multi-cell DC/DC buck converter', International Journal of Simulation and Process Modelling, Vol. 11, No. 2, pp.127-137.

La Rosa, M., Rabinovich, M.I., Huerta, R., Abarbanel, H.D.I. and Fortuna, L. (2000) 'Slow regularization through chaotic oscillation transfer in an unidirectional chain of Hindmarsh-Rose models', Physics Letters A, Vol. 266, No. 1, pp.88-93.

Lega, L., Guzzo, M. and Froeschlé, C. (2016) 'Theory and applications of the Fast Lyapunov indicator (FLI) method', in Skokos, C. et al. (Eds.): Chaos Detections and Predictability, Lecture Notes, pp.35-54.

Li, X.F., Chlouverakis, K.E. and Xu, D.L. (2009) 'Nonlinear dynamics and circuit realization of a new chaotic flow: a variant of Lorenz, Chen and Lü', Nonlinear Analysis: Real World Applications, Vol. 10, No. 4, pp.2357-2368.

Lobsiger, Y. and Kolar, J.W. (2015) 'Closed-loop di/dt and dv/dt IGBT gate driver', IEEE Transactions on Power Electronics, Vol. 30, No. 6, pp.3402-3417.

Maffione, N.P., Giordano, C. and Cincotta, P. (2011) 'Testing a fast dynamical indicator: the MEGNO', International Journal of Nonlinear Mechanics, Vol. 46, No. 1, pp.23-34.

Meynard, T. (2014) 'Introduction and overview on multi cell and multi level for high power and high voltage applications', ECPE Workshop Advanced Multicell/Multilevel Power Converters, 1-2 July 2014, Toulouse, France.

Meynard, T.A. and Foch, H. (1992) Electronic Device for Electrical Energy Conversion between a Voltage Source and a Current Source by Means of Controllable Switching Cells, European Patent, 92/916336.8.

Skokos, C.H. (2017) 'The Lyapunov characteristic exponents and their computation', Lecture Notes in Physics, Vol. 790, pp.63-135, Springer Berlin.

Skokos, C.H. and Manos, T. (2016) 'The smaller (SALI) and the generalized (GALI) alignment indices: efficient methods of chaos detection', in Skokos, C. et al. (Eds.): Chaos Detection and Predictability, Lecture Notes, pp.129-181.

Tremori, A., Agresta, M. and Ferrando, A. (2016) 'Simulation of autonomous systems in the extended marine domain', International Journal of Simulation and Process Modelling, Vol. 11, No. 1, pp.9-23. 
Vazquez, G., Martinez-Rodriguez, P.R., Escobar. G., Sosa, J.M. and Martinez-Mendez, R. (2016) 'A PWM method for single-phase cascade multilevel inverters to reduce leakage ground current in transformerless PV systems', International Transactions on Electrical Energy Systems, Vol. 26, No. 11, pp.2353-2369.
Wei, Z. and Yang, Q. (2011) 'Dynamical analysis of a new autonomous 3-D chaotic system only with stable equilibria', Nonlinear Anal.: Real World Applications, Vol. 12, No. 1, pp.106-118.

Zhou, W., Xu, Y., Lu, H. and Pan, L. (2008) 'On dynamics analysis of a new chaotic attractor', Physics Letters A, Vol. 372, No. 36, pp.5773-5777. 